\title{
Effect of stress management intervention on stress response and job satisfaction among employees in Chinese auto enterprises
}

\author{
Sheng-jun Wu, Yunge Wang, Hong Dai, Xu-feng Liu* \\ Faculty of Military Medical Psychology, Air Force Military Medical University
}

\begin{abstract}
Objective: To understand the effect of stress management interventions on improving stress response and job satisfaction among auto company employees. Method: A total of $320 \mathrm{em}-$ ployees in three Chinese auto companies were selected in August 2017 by stratified random sampling method to detect the stress response and job satisfaction. According to the score of job satisfaction, we got the low job satisfaction group (experimental group, $\mathrm{n}=86$ ) and high job satisfaction group (control group, $n=86$ ). The two groups accepted a twelve months stress management intervention and then the stress response and job satisfaction scores were measured in August 2018 to learn the intervention effect. Results: The stress response score had a significant correlation with the job satisfaction score $(r=0.219$, $P<0.05)$. After the intervention, the stress response and job satisfaction scores in experimental group was significantly higher than that before intervention $(19.38 \pm 9.54,16.00 \pm 10.47, P<0.05)$. The job satisfaction score was significantly higher than that before intervention $(11.07 \pm 4.59,2.89 \pm 1.96, P<0.01)$. Conclusion: Stress management intervention can improve the stress response and job satisfaction of auto enterprise employees.
\end{abstract}

\section{Keywords:}

Auto enterprise employees; Stress management; Stress response; Job satisfaction
*Correspondence to Author:

Xu-feng Liu

Faculty of Military Medical Psychology, Air Force Military Medical University

How to cite this article:

Sheng-jun $\mathrm{Wu}$, Yunge Wang, Hong Dai, Xu-feng Liu. Effect of stress management intervention on stress response and job satisfaction among employees in Chinese auto enterprises. International Journal of Psychological Research and Reviews, 2019, 2:8

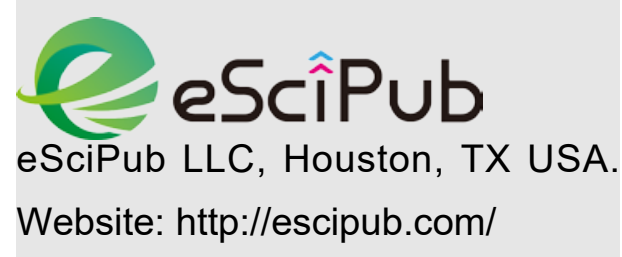

Website: http://escipub.com/ 


\section{Introduction}

With the popularization of automobiles, the competition among domestic and foreign automobile manufacturing enterprises intensifies, and the employees of automobile enterprises face severe challenges such as long working hours and great intensity. The upsurge of workplace and life pressure leads to the negative pressure response of the employees of auto enterprises, which is mainly manifested as the upsurge of negative emotions and social dysfunction. Under this situation, the positive psychological feelings of employees in the auto industry their job satisfaction are also seriously reduced which could affect the work performance of employees and increases the risk of demission. How to help employees act well in stress management and improve their job satisfaction has become an important issue that cannot be ignored in the human resource management of vehicle enterprises ${ }^{[1-2]}$. Some studies have found in many occupational fields that, through a series of stress-reducing intervention measures such as pressure management group counseling and individual psychological counseling, the job satisfaction of miners, customer service employees and other professional groups can be effectively improved [3-5]. However, there is no research on the stress management intervention to understand its response to the pressure of employees in the auto industry impact of job satisfaction. Therefore, we conducted general education guidance and pressure management intervention training for high scores and low scores of employees in some Chinese auto enterprises, and the pressure response and job satisfaction changes of the two groups of employees were measured before and after the training, so as to give some suggestion of pressure management methods.

\section{Methods and subjects}

\section{Subjects}

In August 2017, the stratified random sampling method was adopted to select 172 employees (average age 30 years old, range 21 to 52 years old) of five auto enterprises in China. The pressure response and job satisfaction were measured in all the subjects. The subjects were randomly divided into two groups, that is experimental group $(n=86)$ and control group $(n=86)$ There was no statistically significant difference in the demographic variables between the two groups $(P>0.05)$. See table 1 .

\section{Table 1 The basic information of experimental group and control group}

\begin{tabular}{|c|c|c|c|c|c|c|c|c|}
\hline \multirow[t]{2}{*}{ Group } & \multirow[t]{2}{*}{ Number } & \multirow[t]{2}{*}{ Age } & \multicolumn{2}{|c|}{ Gender } & \multicolumn{2}{|c|}{ Position } & \multicolumn{2}{|c|}{ Education } \\
\hline & & & Male & Female & Management & Employee & Undergraduate or above & High school of below \\
\hline Experimental group & 86 & $29.19 \pm 5.27$ & 80 & 6 & 20 & 66 & 61 & 25 \\
\hline Control group & 86 & $30.61 \pm 5.41$ & 78 & 8 & 15 & 71 & 57 & 29 \\
\hline$t / x^{2}$ & & 1.63 & \multicolumn{2}{|c|}{0.31} & \multicolumn{2}{|c|}{0.90} & \multicolumn{2}{|c|}{0.43} \\
\hline$P$ & & 0.11 & \multicolumn{2}{|c|}{0.58} & \multicolumn{2}{|c|}{0.34} & \multicolumn{2}{|c|}{0.51} \\
\hline
\end{tabular}

\section{Methods}

The experimental group received pressure management intervention once a month for 12 months, mainly including group psychological counseling, individual psychological counseling and release of decompression emails. The control group received general education guidance in the form of traditional supervisor conversation.

\section{Research tools}


Index of job satisfaction scale (Overall Job Satisfaction Questionnaire)

This scale was establishment by Brayfield and Rothe [6]. It measures employees' general job satisfaction, that is, their overall satisfaction with their work. It combines three dimensions, which are overall satisfaction, salary and welfare and external satisfaction. Overall satisfaction mainly measures the degree of matching between employees' specialties and hobbies, the number of learning opportunities brought by the post itself and the level of job security. Salary and welfare mainly includes salary, benefits, career development prospects and reputation. External satisfaction mainly includes personal satisfaction with the working atmosphere and good interpersonal relationship with superiors and colleagues. This scale is a 5-point Likert scale which can be divided into 5 grades, that is strongly disagree, disagree, uncertain, agree and strongly agree. According to the degree of agreement, 1 to 5 points are assigned in order. A total of 6 items were included. All items were scored positively. The higher the score is the higher the job satisfaction. Domestic studies have shown that the Chinese version of the scale has good reliability and validity [7].

\section{Stress response questionnaire (SRQ)}

$\mathrm{SRQ}$ is used for measure the psychological, physiological and behavior response of subjects' in stress. It includes 28 items and 5-point Likert scale is used, 1 for absolutely yes, 2 for basic yes, 3 for medium, 4 for basic no and 5 for absolutely no, and the higher the total score, the lower the pressure response. The scale Cronbach's alpha of SRQ was 0.902 , the correlation between it with SAS and SDS was 0.585 and 0.674 , and the retest reliability was $0.913^{[8]}$.

\section{Quality control}

Test personnel were trained to master the test method of paper and pencil test, and the field test was in accordance with the process of group psychological test requirements. The questionnaires were checked and collected after the test is completed.

\section{Statistical analysis}

SPSS 22.0 software was used for statistical analysis. Independent sample $t$ test and correlation analysis were used for the comparison of inter-group differences in the measurement data.

\section{Results}

Relationship between stress response and job satisfaction

The survey showed that the stress response score was $16.21 \pm 11.05$ and the job satisfaction score was $9.73 \pm 6.82$, and the correlation between stress response and job satisfaction was $0.524(P<0.01)$.

\section{Effect of pressure crisis intervention on the stress response}

The results showed that the stress response scores of experimental group were significant higher after training than before $(P<0.05)$ which indicated that the experimental group performed lower stress response after training. There was no significant difference in the pressure response scores of the control group before and after the training $(P>0.05)$. Results are shown in table 2.

\section{Effect of pressure crisis intervention on the job satisfaction}

The results showed that the job satisfaction scores of experimental group were significant higher after training than before $(P<0.01)$ which indicating that the experimental group had higher job satisfaction after training. There was no significant difference in the job satisfaction of the control group before and after the training $(P>0.05)$. Results are shown in table 3. 
Table 2 The comparison of stress response of two groups between before and after training

\begin{tabular}{llllll}
\multicolumn{7}{c}{$(\overline{\mathrm{x}} \pm \mathrm{sd})$} & \\
\hline Group & Number & Before training & After training & $t$ & $P$ \\
\hline Experimental group & 86 & $16.57 \pm 10.08$ & $21.61 \pm 9.04$ & 3.45 & 0.00 \\
Control group & 86 & $17.18 \pm 9.86$ & $18.29 \pm 9.18$ & 0.76 & 0.45 \\
\hline
\end{tabular}

Table 3 The comparison of job satisfaction of two groups between before and after training

\begin{tabular}{llllll}
\hline Group & Number & Before training & After training & $t$ & \\
\hline Experimental group & 86 & $15.04 \pm 2.36$ & $18.77 \pm 3.79$ & 7.75 & 0.00 \\
Control group & 86 & $16.68 \pm 2.03$ & $17.19 \pm 3.51$ & 1.17 & 0.25 \\
\hline
\end{tabular}

\section{Discussion}

The improvement of employees' job satisfaction is an important part of the non-compensation and welfare of the enterprise, and the stress management intervention plays an indispensable role in it. The results of this study showed that there is a significant correlation between stress response and job satisfaction. Suitable stress management intervention training for employees can effectively reduce their stress response and improve their job satisfaction.

In this study, a sample survey of 280 automobile companies found that employees' stress response scores were significantly correlated with job satisfaction, which was consistent with the research results of Zhou et al. [9]. There are many stressors for employees in auto enterprises. Firstly, it's pressure from work itself, especially the work pressure of ordinary front-line employees. They mainly face the negative factors such as long working hours, high labor intensity, high skill requirements and relatively low salary. Secondly, the pressure from the family is mainly caused by the lack of care for the family due to the shift system in the manufacturing industry, and the social support from the family and friends is also relatively insufficient [2]. Under the influence of these negative factors, the pressure response of employees in auto enterprises could rise easily. If it cannot be properly conducted and adjusted, the pressure will seriously affect mental health and work enthusiasm, as well as work satisfaction, which will eventually lead to a rise in the turnover rate. The high turnover rate is harmful for the talent retention and the control of product quality. In the past, salary was often used to compensate for the negative impact of employee job satisfaction decline. However, with the development of management science, the use of non-compensation to solve the problem of job satisfaction decline has become a common concern in many industries ${ }^{[4]}$. Based on the results of the close correlation between stress response and job satisfaction in this study, it is the focus of this study to further explore the role of stress management intervention, a non-salary measure to improve job satisfaction. Training intervention results showed that the stress response of the experimental group was significantly reduced after the stress management intervention, indicating the effectiveness of the intervention which was similar to previous results in other occupational fields. The group psychological counseling of pressure management is a common project of the employee assistance program through 
several stages of group activities, from guiding the employees to understand the generation and performance of pressure to master the skill of pressure management, so that trainees can fully master the psychological skills of self-decompression ${ }^{[3]}$. In addition, in this study, in order to take into account the high stress response of some employees, it was impossible to use group psychological support for all of them. The results showed that the stress management intervention mentioned above has indeed played an important role in improving the stress response of the employees in the auto industry. In addition, the research results in this study also indicated that the work satisfaction of the employees in the experimental group has been significantly improved after the pressure management intervention, indicating that the pressure intervention is indeed a non-salary method to effectively improve work satisfaction and can be an effective complement to the salary method. With the diversification of employee demands, the decline effect of employee satisfaction cannot be fully compensated by the pure economic stimulus of compensation. The importance of paying attention to the psychological needs of employees, especially the problem of employee stress relief, has gradually become prominent. To sum up, the study found that there was a significant correlation between the stress response and job satisfaction of the employees of auto enterprises and stress management intervention training showed that the stress management intervention could effectively reduce the performance of the employees of auto enterprises and improve their job satisfaction. This research provides a new way of thinking to solve the problem of declining employee satisfaction, and also provides a reference for the industry to carry out the stress management intervention practice.

\section{References}

1. Kim, Y., Kim, S. (2018). Job insecurity and depression among automobile sales workers: A longitudinal study in South Korea. American Journal of Industrial Medicine, 61, 140-147.

2. Jeon, I. S., Jeong, B. Y., Jeong, J. H. (2016). Preferred 11 different job rotation types in automotive company and their effects on productivity, quality and musculoskeletal disorders: comparison between subjective and actual scores by workers' age. Ergonomics, 59, 1318-1326.

3. Jeon, I. S., Jeong, B. Y. (2016). Effect of Job Rotation Types on Productivity, Accident Rate, and Satisfaction in the Automotive Assembly Line Workers. Human Factors and Ergonomics IN Manufacturing \& Service Industries, 26, 455-462.

4. Yang, H. X., Song, J. X., Wang, Q. L., Niu, G. Y., Cui, K. K., Feng, J. W. (2013). The influence of stress reduction training group on miners' burnout. Chinese Journal of Coal Industry Medicine, 16(4): 663-665.

5. Yuan, Y. Y. (2017). The application of nurse stress management in nurse management. Journal of Clinic Nursing's Practicality, 2(44): 159.

6. Wanous, J. P., Reichers, A. E., Hudy, M. J. (1997). Overall job satisfaction: how good are single-item measures. Journal of Applied Psychology, 82(2): 247-252.

7. Xu, Z, Y., Zhao, Z, H. An empirical research of job satisfaction of Beijing primary school teachers. Teacher Education Research, 2012, 24(1): 85-92.

8. Zhong, X., Jiang, Q. J., Qian, L. J., Wu, Z. X. (2005). Correlation between stress reaction and social support, life events, coping style in medical personnel. Chinese Journal of Clinical Psychology, 13(1): 70-72.

9. Zhou, J. D., Lin, Q. H., Han, W. L., Fan, Y, Y., Wang, J. (2013). Job satisfaction and its influencing factors among managers in a Sino-Japanese joint venture. Occupation and Health, 2013, 29(9): 1025-1027.

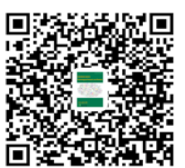

